\title{
BMJ Open How universal are universal preschool health checks? An observational study using routine data from New Zealand's B4 School Check
}

\author{
Sheree Gibb, ${ }^{1,2}$ Barry Milne, ${ }^{2,3}$ Nichola Shackleton, ${ }^{2,3}$ Barry J Taylor, ${ }^{2,4}$ \\ Richard Audas 2,5
}

To cite: Gibb S, Milne B, Shackleton N, et al. How universal are universal preschool health checks? An observational study using routine data from New Zealand's B4 School Check. BMJ Open 2019;9:e025535. doi:10.1136/ bmjopen-2018-025535

- Prepublication history and additional material for this paper are available online. To view these files, please visit the journal online (http://dx.doi org/10.1136/bmjopen-2018025535).

Received 22 July 2018 Revised 27 February 2019 Accepted 1 March 2019

\section{Check for updates}

(c) Author(s) (or their employer(s)) 2019. Re-use permitted under CC BY-NC. No commercial re-use. See rights and permissions. Published by BMJ.

${ }^{1}$ Department of Public Health, University of Otago Wellington, Wellington, New Zealand

${ }^{2}$ A Better Start National Science Challenge, Dunedin, New Zealand

${ }^{3}$ Centre of Methods and Policy Application in the Social

Sciences, University of Auckland, Auckland, New Zealand ${ }^{4}$ Department of the Dean, University of Otago, Dunedin, New Zealand

${ }^{5}$ Department of Women's and Children's Health, University of Otago, Dunedin, New Zealand

Correspondence to

Dr Sheree Gibb;

sheree.gibb@otago.ac.nz

\section{ABSTRACT}

Objectives We aimed to estimate how many children were attending a universal preschool health screen and to identify characteristics associated with non-participation. Design Analysis of population-level linked administrative data.

Participants Children were considered eligible for a B4 School Check for a given year if:(1) they were ever resident in New Zealand (NZ),(2) lived in NZ for at least 6 months during the reference year, (3) were alive at the end of the reference year, (4) either appeared in any hospital (including emergency) admissions, community pharmaceutical dispensing or general practitioner enrolment datasets during the reference year or (5) had a registered birth in NZ. We analysed 252273 records over 4 years, from 1 July 2011 to 30 June 2015.

Results We found that participation rates varied for each component of the B4 School Check (in 2014/2015 $91.8 \%$ for vision and hearing tests (VHTs), $87.2 \%$ for nurse checks (including height, weight, oral health, Strengths and Difficulties Questionnaire [SDQ] and parental evaluation of development status) and $62.1 \%$ for SDQ - Teacher [SDQ-T]), but participation rates for all components increased over time. Māori and Pacific children were less likely to complete the checks than non-Māori and nonPacific children (for VHTs: Māori: OR=0.60[95\% Cl 0.61 to 0.58 ], Pacific: $\mathrm{OR}=0.58[95 \% \mathrm{Cl} 0.60$ to 0.56$]$, for nurse checks: Māori: $\mathrm{OR}=0.63[95 \% \mathrm{Cl} 0.64$ to 0.61], Pacific: OR=0.67[95\% Cl 0.69 to0.65] and for SDQ-T: Māori: OR=0.76[95\% Cl 0.78 to 0.75], Pacific: $0 R=0.37[95 \% \mathrm{Cl}$ 0.38 to 0.36$]$ ). Children from socioeconomically deprived areas, with younger mothers, from rented homes, residing in larger households, with worse health status and with higher rates of residential mobility were less likely to participate in the B4 School Check than other children. Conclusion The patterns of non-participation suggest a reinforcing of existing disparities, whereby the children most in need are not getting the services they potentially require. There needs to be an increased effort by public health organisations, community and whānau/family to ensure that all children are tested and screened.

\section{INTRODUCTION}

Globally, a common practice in childhood development is to screen children to
Strengths and limitations of this study

Whole population sample of all children completing B4 School Check over 4 years $(n=252273)$.

- Using linked data from different sectors provided information about a wide range of characteristics.

- Only bivariate analyses were possible; sample loss due to missing data meant that multivariate analysis was not feasible.

determine if there are any key developmental problems that need to be assessed. ${ }^{1}$ These screens typically check for problems relating to general health, including hearing, vision, height, weight and oral health. They also often screen for emotional, behavioural or intellectual issues that might be evident. ${ }^{2}$ Hall and Stewart-Brown ${ }^{3}$ categorise four types of screening programmes: (1) biochemical; (2) screening involving objective measures (such as height and weight, vision and hearing); (3) screening involving physical examination; and (4) screening involving understanding of child development.

In New Zealand (NZ), the screen is called the B4 School Check (B4SC), and it is administered to children aged 4 years. It is the final and most comprehensive in a series of eight free Well Child Tamariki Ora visits that children receive, ${ }^{4}$ and currently the only one for which comprehensive linked data are available to examine coverage. The B4SC was implemented in NZ starting in September 2008, although it was not universal until 2010. There are eight key developmental areas that are assessed: vision, hearing, oral health, general health, growth measurement, strengths and difficulties (Strengths and Difficulties Questionnaire [SDQ]) as reported by parents and teachers and a parental evaluation of development status (PEDS). If concerns are identified in any 
area, children are referred for further testing or intervention. The B4SC is administered by the Ministry of Health, which has set a target $90 \%$ participation rate across the country, with parents and guardians being notified of the B4SC via enrolment with a primary health organisation (PHO; organisations that provide primary care services ${ }^{5}$ ). The Ministry's data suggest they have been meeting their target since 2013, but compliance falls short of $100 \%{ }^{6}$ Furthermore, not all children are registered with a $\mathrm{PHO}$ (95\% of children aged $0-4$ years are registered ${ }^{7}$ ), and including unregistered children in the denominator will further reduce compliance rates.

This raises three concerns: first, that a non-trivial number of children are missing their checks. Second, that some children may not be registered with a PHO and, as such, their parents are not notified that their child should attend a B4SC. Third, that these children may be more likely to be in higher risk categories for later health problems and could benefit from the referrals to interventions that accompany this screen. It is this final concern that is the focus of this study.

\section{EVIDENCE PRESCHOOL/SCHOOL ENTRY SCREENING PARTICIPATION}

Across different universal health checks available to the adult populations of different countries certain patterns persist: those in poorer socioeconomic circumstances, with lower qualifications and at greater risk of health problems are less likely to attend such checks. ${ }^{8-13}$

The available evidence for universal health checks in childhood suggests a similar pattern. ${ }^{14-16}$ Wood et al ${ }^{15}$ considered the coverage of universal child health reviews in Scotland. They considered two cohorts of children, the first, born in 1998/1999 were eligible for five health checks ( 10 days/ $6-8$ weeks/8-9 months/22-24 months and $39-42$ months) and a second cohort, born in 2007/2008, were only eligible for the first two checks. They found that coverage rates of the 10-day check were very high in both cohorts $(99 \%)$, but this declined as the children aged. For the review of $6-8$ weeks, coverage was between $94 \%$ and $95 \%$, and for the review of $39-42$ months, the coverage rates fell to $86 \%$. There were clear deprivation gradients, with children living in the least deprived areas much more likely to have a health check than those in the most deprived areas, and these gradients increased substantially with increasing age and decreasing coverage. They conducted an audit on a subset of the areas included in the review (Glasgow and Fife). Consistent with the inverse care law, ${ }^{17}$ they found that children who missed the review of 6-8 weeks were more likely to require additional health services and support in the future than those who attended the review.

Similarly, evidence from Denmark suggests that participation declines with age. Only $76 \%$ of eligible children attend the age 4 health screen. Child, parent and household level characteristics predicted attendance with children who had been hospitalised at least twice since birth, children of single, younger, less educated or immigrant parents and children residing in low-income households or living in institutions less likely to participate. ${ }^{16}$ Similarly, in North Carolina, children of mothers who were younger, less educated, black and unmarried were also less likely to receive an adequate number of well child visits. $^{14}$

The overall aim of these universal checks is to identify children who are at risk of later problems and direct them towards interventions that will reduce this risk. The early identification of health and developmental issues increases the efficacy and cost-effectiveness of treatment and lessens the risk of any potential comorbidities. However, evidence about whether childhood screening achieves this aim is mixed. ${ }^{18-20}$ Childhood screening relies on accurate identification of children at risk and also on the availability of effective interventions or treatments for at-risk children, which are not always available. ${ }^{19} 21$ Regardless, universal checks are often the only instrument to identify children in need of additional services, who may otherwise be missed by the health system. Therefore, systematic differences in attendance highlight a crucial issue: those children most in need are missing out on vital services.

In NZ, we are in a unique position to examine the characteristics of those not completing the B4SC. Many routinely collected government databases (including B4SC) are held in the Statistics New Zealand Integrated Data Infrastructure (IDI) and each individual is assigned a unique identifier that allows their records to be linked across data files. In this analysis, we build a population cohort using birth records and immigration/emigration files to determine which children aged 4 years were in the country and eligible for the B4SC between 1 July 2011 to 30 June 2015, and then we examine the characteristics of those who do not get the B4SC.

The aim of this paper is to identify characteristics associated with non-participation in the B4SC by linking to deprivation, birth, census, health, disability and immunisation records, all of which are available in the IDI.

\section{METHODS}

\section{Study design}

This study was an observational study using routine data from NZ's IDI.

\section{Data sources and linkage}

All data were sourced from the IDI, ${ }^{22}$ a secure database containing anonymised microdata about individuals.

\section{B4 School Check}

The main outcome measures for this study were generated from B4SC data. The B4SC is a universal programme offered to all families in NZ with 4-year-old children. ${ }^{23}$ If a child is enrolled with a PHO, a letter or email will be sent to parents inviting them to bring the child along for a B4SC. Parents can also request a check by approaching 
a general practitioner (GP) or other B4SC provider. The checks are carried out by registered nurses or nurse practitioners with experience in child health, with assistance from vision and hearing technicians. ${ }^{4}$ One component (SDQ - Teacher) is completed by a child's early childhood education (ECE) teacher, who receives the SDQ directly from the B4SC provider and is responsible for returning it to the provider. ${ }^{24} \mathrm{ECE}$ coverage is high in $\mathrm{NZ}$ with more than $95 \%$ of children enrolled in ECE in the 6 months prior to starting school. ${ }^{25}$ The B4SC is undertaken in different locations including preschools, kōhanga reo (Māori language immersion early childhood education centres), doctors' clinics and other community venues such as churches and marae (meeting grounds and focal points for Māori communities), depending on the needs of the community. In some cases, parts of the B4SC are carried out in the child's home.

The percentage attending the B4SC was estimated as $79 \%$ in $2011 / 2012,80 \%$ in $2012 / 2013,91 \%$ in $2013 / 2014,92 \%$ in $2014 / 2015$ and $92 \%$ in $2015-2016 .{ }^{6}$ High coverage of vulnerable groups (Māori children and children from areas of high socioeconomic deprivation) is encouraged by linking a portion of District Health Board (see ref 26) funding for B4SC to achieving a specified level of coverage for these groups. In 2015/2016, the coverage for Māori children was $88 \%$ and for Pacific children it was $89 \% .{ }^{27}$ For children from high deprivation areas, the coverage was $93 \% .{ }^{6}$ This paper uses data from B4SC completed between the fiscal years 2011/2012 and 2014/2015.

\section{Other datasets}

Datasets used to construct the other analysis variables for this study were: Census 2013; Ministry of Health PHO enrolment and hospital discharge datasets; source ranked ethnicity; address notification; SOCRATES; and birth registrations. More detail on the variables constructed from these datasets can be found in the Other analysis variables section below.

\section{Study population}

To identify the population of children eligible for a B4SC, annual populations of 4-year-old children were constructed using methods developed previously for constructing populations from the IDI. ${ }^{28}{ }^{29}$ Children were included in the denominator population for a given year if they:

Appeared in any hospital (including emergency) admissions, community pharmaceutical dispensing or $\mathrm{PHO}$ enrolment datasets during the reference year or Had an NZ birth record.

The above population was then restricted to children who lived in NZ for at least 6 months during the reference year, were alive at the end of the reference year, were included in the IDI spine (which aims to cover an 'ever-resident' population including all those who either were born in $\mathrm{NZ}$, migrated to $\mathrm{NZ}$ or paid tax in $\mathrm{NZ}^{30}$ ).
Over the 4-year, period we identified 288753 children who had a health or birth record. Of those, 277593 (96\%) were in the IDI spine and 252273 of those $(91 \%)$ were alive and resident in $\mathrm{NZ}$ at the end of their reference year and were used as the denominator population.

To examine whether the above criteria had an impact on study results, we conducted a sensitivity analysis in which we replicated the analysis using two different definitions of the study population. The main conclusions of the study were the same across all replications. The detailed results of the sensitivity analysis can be found in online supplementary appendix 1 .

\section{OUTCOMES}

\section{B4SC completion}

For the purposes of this study, B4SC was grouped into three components: vision and hearing test (VHT) checks (vision and hearing); nurse checks (growth, dental, immunisation, PEDS and SDQ - Parent); and SDQ - Teacher (SDQT). These groupings were developed in consultation with the Ministry of Health and reflect the way in which the components are typically completed (vision and hearing checks are usually completed together by vision and hearing technicians, the nurse checks are usually completed together and SDQ-Teacher is completed separately by a child's early childhood education teacher). In some regions, these groups of checks are administered in separate visits; in other regions, they are combined into a single visit. If a child had completed all checks within a component, they were considered to have completed that component. B4SC coverage was calculated as the number of children completing a B4SC component divided by the total number of children in the population. Completion rates for the individual component checks can be found in online supplementary appendix 2 .

\section{Other analysis variables \\ Ethnicity}

Ethnicity measures were taken from the source ranked ethnicity table in IDI. The table collates ethnicities that are reported to different administrative collections in IDI and ranks these sources to provide an ethnic profile for each individual. Ranking is based on how closely the ethnicities reported for an individual in the administrative source match those reported in the census (census records have highest priority and $84.3 \%$ of the study population had ethnicity sourced from census, followed by birth records [13.9\%], followed by health [1.7\%]). ${ }^{31}$ From this, we constructed four dichotomous ethnicity variables representing whether children were recorded as identifying with each of the following major ethnic groups: Māori, Pacific, Asian and European. Individuals could belong to none, one or more than one of these ethnic groups. Identifying as more than one ethnicity is common in NZ, ${ }^{32}$ and $23.9 \%$ of the current sample belonged to multiple ethnic groups. 


\section{Socioeconomic deprivation}

NZ Deprivation Score (NZDep) was calculated using the standard 2013 NZDep concordance ${ }^{33}$ and the child's meshblock (small geographic area typically containing 30-80 dwellings ${ }^{34}$ ) of usual residence at the time of the fourth birthday, or the first meshblock recorded within 12 months after the date of the fourth birthday if no meshblock was recorded prior to that. Each meshblock was assigned a decile from 1 (least deprived) to 10 (most deprived). These were then grouped into quintiles.

\section{Urbanicity}

The child's meshblock of usual residence was also used to define urbanicity. The standard classification of urban/ rural areas in $\mathrm{NZ}^{35}$ is a five-point scale: (1) main urban (centred on a city or major urban area (population of at least 30000 ), (2) secondary urban (centred on larger regional centres (population 10000-29 999), (3) minor urban (centred around smaller towns (population 10009999), (4) rural centre (population 300-999) and (5) other rural (population <300). These were collapsed into two groups: urban (main urban, secondary urban and minor urban area) and rural (rural centre and other rural).

\section{Residence changes}

The total number of different addresses lived at from birth to fourth birthday (minus one to give the number of changes) was calculated from the address notification table in IDI, which collates address updates reported to data providers.

\section{Hospitalisations}

The following variables were obtained from hospital records: total number of hospital admissions (excluding the child's birth and any emergency department visits that did not result in hospital admission) from birth to fourth birthday; the total number of days spent in hospital for those visits; and total number of emergency department visits from birth to fourth birthday.

\section{GP enrolment}

The extent to which a child had continuous enrolment with a GP was estimated by counting the number of quarters in which a child was enrolled with a PHO (umbrella organisations for GPs) from birth to fourth birthday.

\section{Disability}

Children who received a referral to Disability Support Services before their fourth birthday were classified as having a disability.

\section{Information from birth record}

Birth records were available for $94.1 \%$ of the total sample. The following variables were obtained from the child's birth record: the child's birth weight, in grams; gestational age, categorised into $<37$ weeks, 37-42 weeks and $>42$ weeks; whether a father was recorded on the child's birth certificate; age of the child's mother at the time of the child's birth, grouped into under 20; 20-24; 25-29; 30-34; 35 years and over.

\section{Variables from census records}

Additional variables were obtained by linking to census records. Household variables were obtained by linking to the household form connected to the child's census record; $82.9 \%$ of children had census household information available. Mother and father variables were obtained by first linking to the child's birth record to identify mother and father, and then linking to census records for the mother and father. A percentage of 79.8 of children had mother census information available; $68.5 \%$ had father census information available. All census variables are recorded as at Census day (5 March 2013). The variables from Census were: size of household (including child), grouped into: $2-4$ people, 5-7 people and 8 or more people; whether the dwelling was rented or owned (including those held in family trusts); whether any member of the child's household received benefit income in the year to 5 March 2013; whether the child's mother spoke enough English to have a conversation about everyday things; the highest qualification of the child's mother and father at the time of the 2013 census, classified into: no formal qualifications, high school qualifications, tertiary qualification below bachelor's degree, bachelor's degree or higher; the current smoking status of the child's mother at the time of the census, classified into: current regular smoker, ex-smoker and never smoked.

\section{Analysis}

All analyses were conducted using SAS Enterprise Guide V.9 within the secure data lab environment. First, we constructed the population and calculated rates of those who completed components (VHT, nurse checks and SDQT) of the B4SC. Second, we compared the characteristics of those who did not complete a component compared with those who did by fitting logistic regression models in which B4SC completion was modelled as a function of the relevant predictor. ORs and 95\% CIs were calculated from the logistic regression coefficients.

\begin{tabular}{|c|c|c|c|c|}
\hline Fiscal year & $\mathbf{N}$ & $\begin{array}{l}\mathrm{N}(\%) \mathrm{VHT} \\
\text { complete }\end{array}$ & $\begin{array}{l}N(\%) \text { nurse } \\
\text { checks } \\
\text { complete }\end{array}$ & $\begin{array}{l}\mathrm{N}(\%) \text { SDQ } \\
\text { Teacher } \\
\text { complete }\end{array}$ \\
\hline 2011/2012 & 63714 & 54924 (86.2) & 49986 (78.5) & 33690 (52.9) \\
\hline $2012 / 2013$ & 62664 & 55344 (88.5) & $50814(81.4)$ & $35433(57.3)$ \\
\hline $2013 / 2014$ & 63372 & $57294(90.5)$ & 54183 (85.6) & 37881 (60.0) \\
\hline $2014 / 2015$ & 62529 & $57282(91.8)$ & $54348(87.2)$ & 38379 (62.1) \\
\hline
\end{tabular}

*Nurse $=$ dental, growth, immunisations, PEDS and SDQ-P check. B4SC, B4 School Check; PEDS, parental evaluation of development status; SDQ-P, Strengths and Difficulties Questionnaire - Parent; VHT, vision and hearing test. 


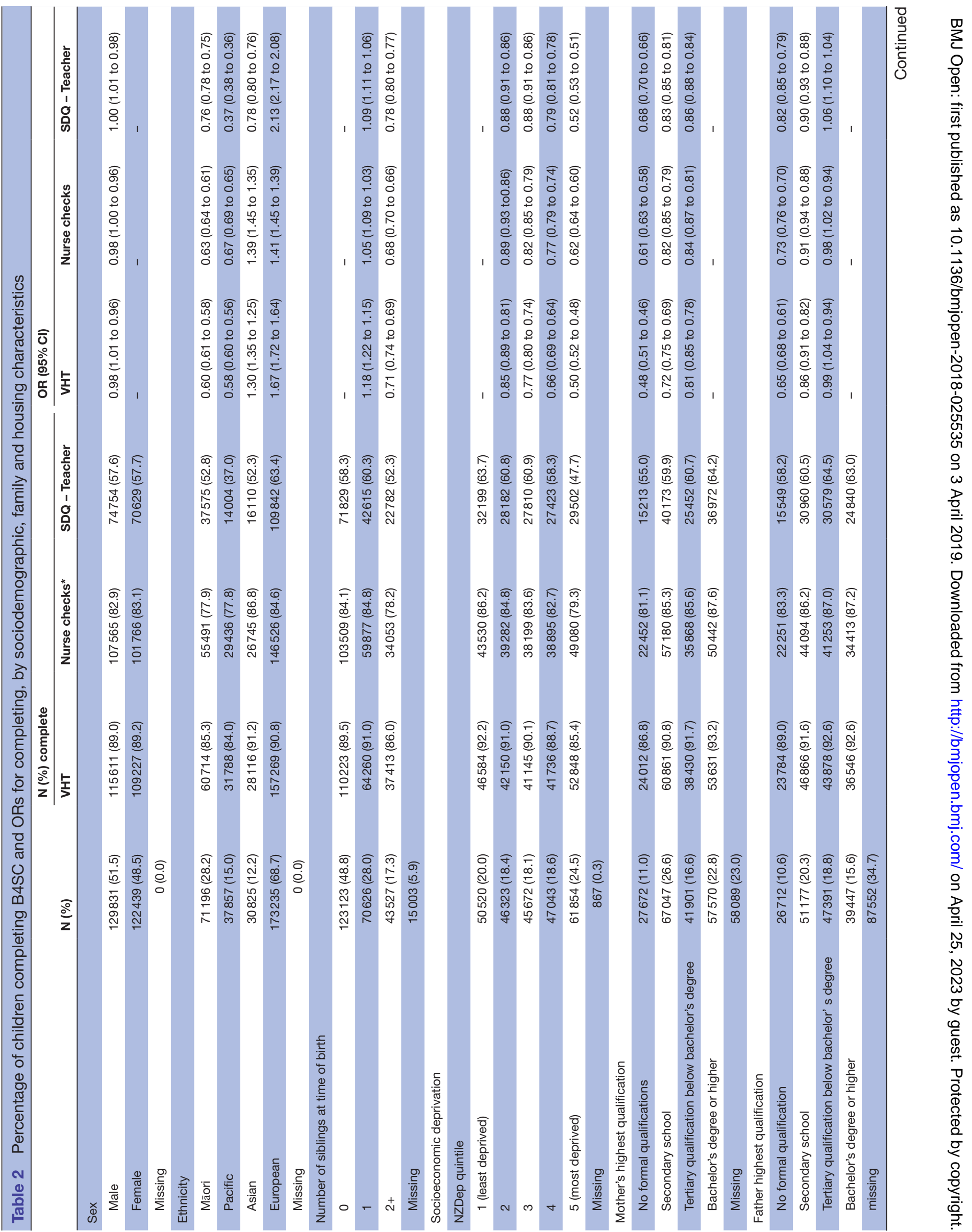




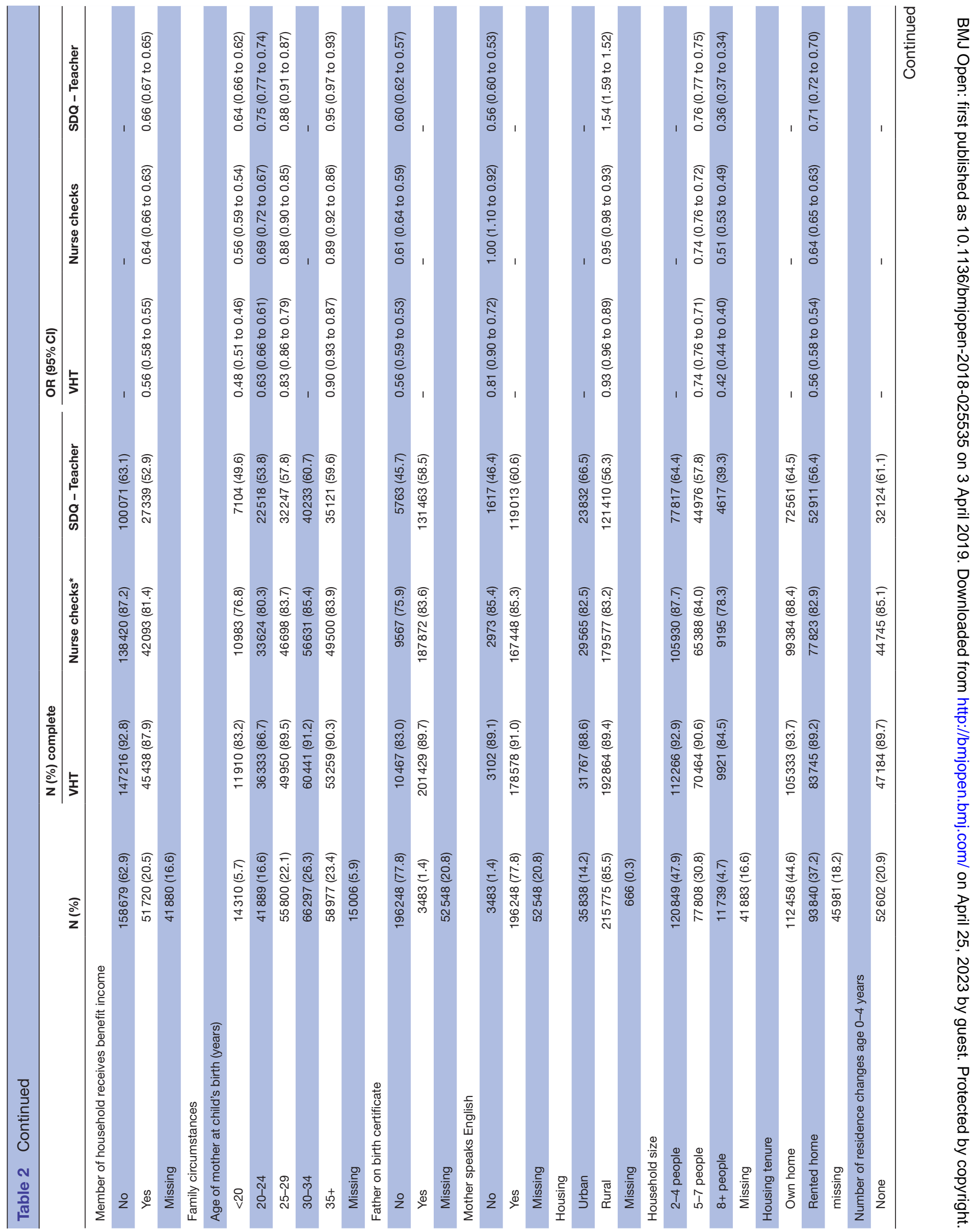




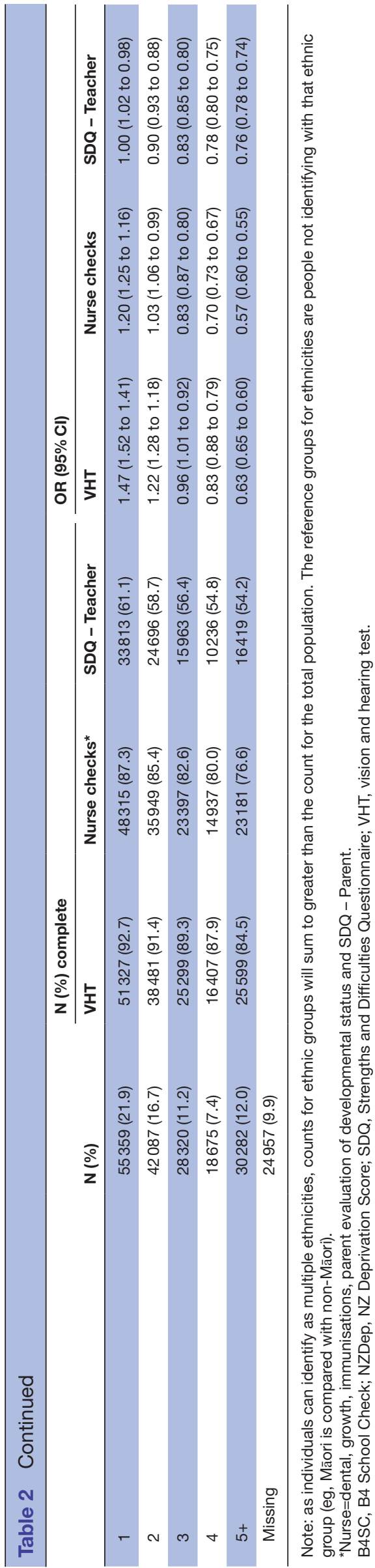

Patient and public involvement

Patients and public were not involved in the design or conduct of this study.

\section{RESULTS}

Table 1 shows the total number of children in the denominator (eligible) population for each year, and the number and percentage of children who completed the VHT, nurse and SDQT components of the B4SC by year. In all years, completion was highest for the VHT component and lowest for the SDQT component. Approximately $52 \%-62 \%$ of children completed the SDQT component, compared with $78 \%-87 \%$ for the nurse components and $86 \%-91 \%$ for the VHT components. Coverage was lowest in 2011/2012 and highest in 2014/2015.

Tables 2 and 3 show the associations between completion of each B4SC component for 2011/2012 to 2014/2015 (all years combined) and a range of characteristics. Sociodemographic characteristics are reported in table 1 and health and perinatal characteristics in table 2. The tables show the number and percentage of children completing each B4SC component, the OR and 95\% CIs.

Most of the sociodemographic characteristics presented in table 1 were significantly associated with B4SC completion. Children were more likely to complete a check if they: were of European (compared with not European) or Asian (compared with not Asian) ethnicity; had fewer siblings; came from areas of lower socioeconomic deprivation; had a mother with a bachelor's degree; had mothers aged 30-34 years; lived in a home that was owned rather than rented; lived in a smaller ( $2-4$ person) household; and lived in a household that does not receive benefit income.

The health and perinatal characteristics presented in table 2 were all significantly associated with B4SC completion. Children were more likely to complete a B4SC if they: had a mother that had never smoked; weighed between $2500 \mathrm{~g}$ and $4000 \mathrm{~g}$ at birth; had a gestational age of between 37 weeks and 42 weeks; were not referred for disability support; spent more time enrolled with a GP; and had lower numbers of hospital and emergency department admissions and spent fewer days in hospital.

\section{DISCUSSION}

Our results demonstrate that Māori and Pacific children, those in poorer socioeconomic circumstances and with poorer health are less likely to complete the B4SC. Children living in areas of higher socioeconomic deprivation, without a father named on the birth certificate, with mothers and fathers with lower levels of education, living in households with five or more people, having multiple changes in residence in the early years of life and living in rental accommodation have a lower likelihood of B4SC completion. Children with indicators of poor health outcomes including having a mother who smokes and having a low birth weight also have a lower likelihood 

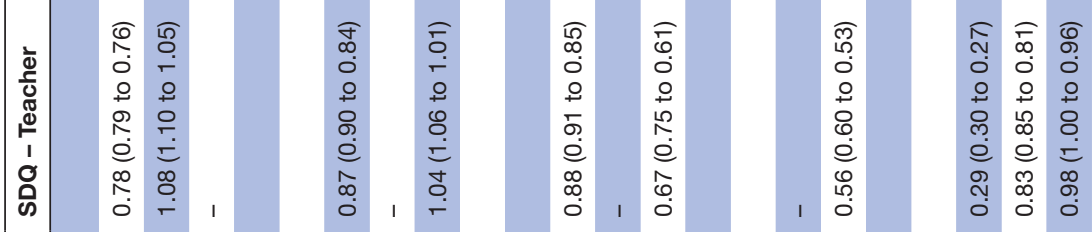

స్ำ

용

듣. बे

ป

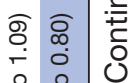

$\stackrel{\circ}{\leftarrow} \stackrel{0}{\circ}$

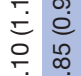

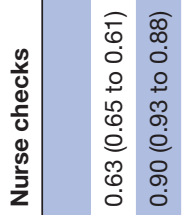

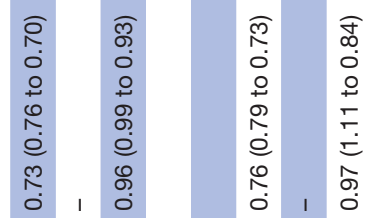

बิ

कำ

สิ

$\circ$ 웅

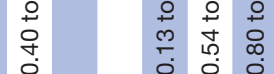

Nָ

กิ

$\stackrel{+}{\circ}+\frac{1}{0}$

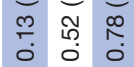

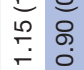

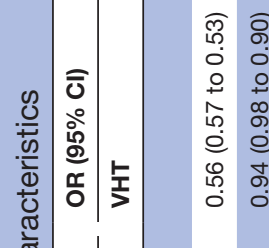

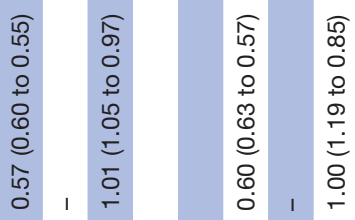

लำ 으 웅

$\begin{array}{llll}0 & 0 & 0 \\ 0 & 0 & 0 & 0 \\ 0 & 0\end{array}$

ले न म

$\begin{array}{llll}0 & 0 \\ 0 & 0 & 0 & 0 \\ 0 & 0 & 0\end{array}$

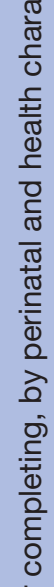

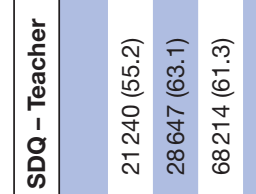

ㄷำ

สุ สิ สุ

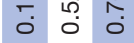

๙ึำ

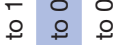

फ़ 아 त

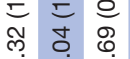

$-0$

造 贺

迎

สุ

สำ เกิ

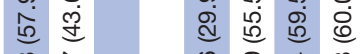

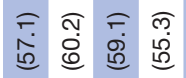

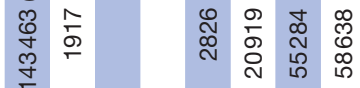

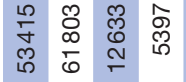

कุ

䠐

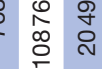

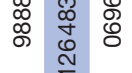

कิ กิ

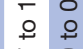

กิ

ঙ̣

ขั ธิก ส

이

กิธ สิ

क

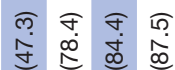

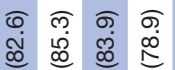

สุ

등 ऽั

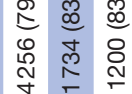

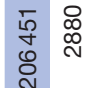

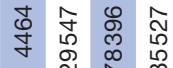

N

ळ $\infty$

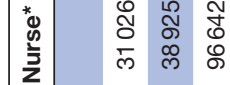

F

$\underset{\leftarrow}{\square}$

N

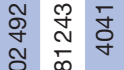

๘

@

อิ อิ

ติ

๘

œ @ @

\๐

ळ

ธก โิ

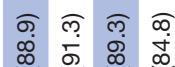

क. ल

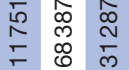

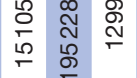

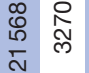

$\infty$ N

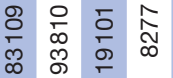

$\infty$ ळ

ลัฐ

స్

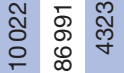

ơ I

กิ อิ

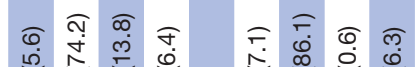

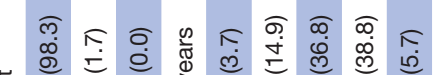

ํ.

âd ช

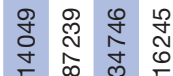

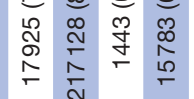

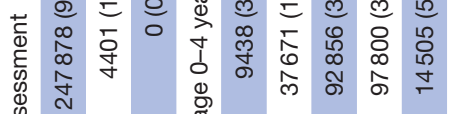

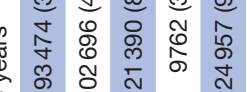

న

స్

$z$ 品
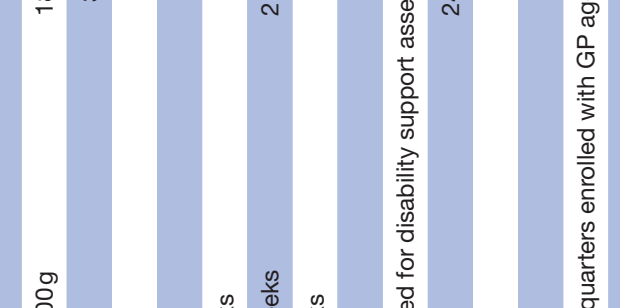

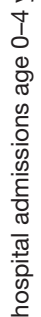

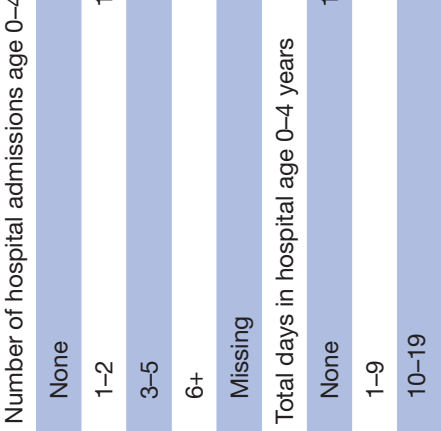

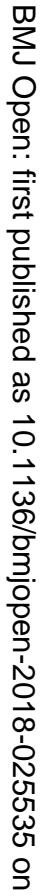

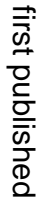

흥.

(

-

咅.

$\stackrel{0}{0}$

일

\%

$\stackrel{3}{3}$

궁

$\frac{\bar{\partial}}{3}$

蛋

을.

ㅇํㅇ

음

을.

N

స్ల

Q

을

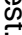

뭉

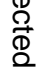

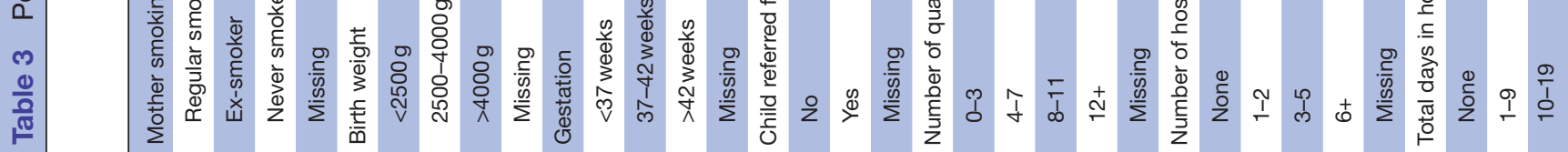




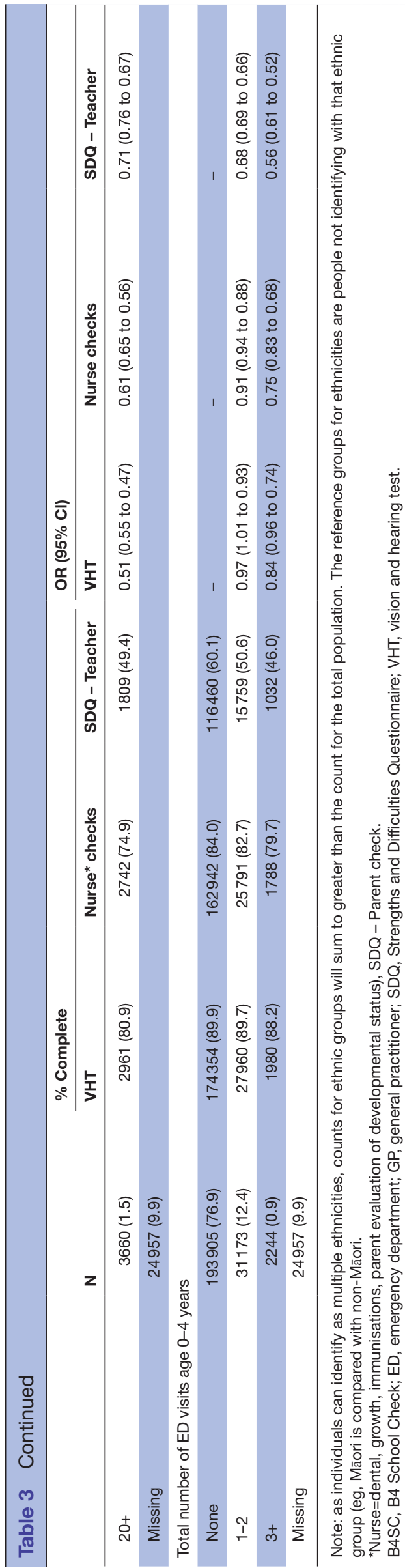

of B4SC completion. Given that these factors tend to be associated with poorer child health outcomes, ${ }^{36}{ }^{37}$ our results paint a consistent pattern, demonstrating that across a wide range of measures of vulnerability, those children who would potentially most benefit from a B4SC screen, and the referrals to interventions are less likely to participate.

A strength of this study is the large, linked dataset that was used (the IDI). The IDI is a whole population data source, and therefore, it allows us to include children who are often excluded from other analyses, such as those not in regular contact with health services. Furthermore, the large number of data sources included in the IDI allows us to examine a wider range of characteristics than would be available in any single source.

While this study is novel and provides vital information for service providers, all of the analyses presented in this paper are bivariate. It is likely that children who are disadvantaged in one area are also at a disadvantage in other areas (ie, the predictors of B4SC completion are correlated). Multivariate analysis would provide more detailed information about the joint or relative impact of different predictors on B4SC completion. However, to run multivariate analysis, we would have to restrict our sample to children born in NZ, with a mother and father who completed 2013 census. These restrictions would reduce the sample to less than $70 \%$ of the total sample and would exclude all migrants, making the results difficult to generalise to the whole population. For this reason, we have chosen not to undertake multivariate analysis in this paper.

Our findings are consistent with existing literature on the coverage of child health checks ${ }^{14-16}$ and provide further support for the inverse care law-that those with the greatest need are the least likely to seek services. ${ }^{17}$ There is currently very little research in this area for child health screens, but the application of the inverse care law is a consistent finding among free health checks for the adult population. ${ }^{8-13}$ However, the reasons why people most in need do not attend are not well understood, and there is a need for qualitative research investigating why parents are not taking children to free health checks.

Several potential explanations for non-attendance at adult health checks have been put forward that may be applicable to child health checks including lack of awareness, time constraints and access issues, ${ }^{10}$ and misunderstanding the purpose/scepticism. Focus groups conducted with low income Māori and Pacific parents have identified concerns about relevance of the B4SC checks, children and parents being judged and language and cultural understanding as potential barriers to participation. ${ }^{38}$ Lack of awareness of the checks was also identified as a problem, and this may be a particular issue for children who are not enrolled on the PHO system $(5 \%$ of children) or who have incorrect address information and thus do not receive the invitation letter. Access could also be an issue with many of the B4SC being carried out by Plunket or other health services that are 
only open during normal office hours and not at weekends. ${ }^{3839}$ Therefore, households where both parents work or single-parent working households will not easily be able to attend. Furthermore, for less densely populated regions in NZ, there are fewer centres offering B4SC, compared with more densely populated regions such as Auckland, Wellington or Christchurch, ${ }^{39}$ meaning it is less convenient to attend. Scepticism about the value of attending and the purpose of the screens is likely to differ by ethnic group, as research persistently demonstrates that Māori receive a poorer quality and slower service and are less likely to receive appropriate levels of care. ${ }^{40-42}$ There are similar findings for Pacific peoples also. ${ }^{43-45}$ Therefore, these groups may be less trusting of the NZ health system. ${ }^{46}$

Socioeconomic and ethnic inequalities in healthseeking and health outcomes within NZ are well documented for both the adult and child population. ${ }^{44} 4547 \mathrm{~A}$ long-standing objective of the NZ government is to reduce health and socioeconomic disparities, particularly for Māori and Pacific families. Patterns of participation at the B4SC could be reinforcing existing ethnic and socioeconomic disparities. Early intervention is one means of reducing inequities. ${ }^{48}{ }^{49}$ Although evidence for the effectiveness of childhood screening is mixed, at present, it appears that any potential benefits that do result from the B4SC will be unevenly distributed across ethnic and socioeconomic groups. Improving B4SC participation would be a cost-effective path towards converging outcomes and would ensure that any benefits from the screen are reaching children who are most at risk of later health concerns.

Although $100 \%$ attendance in the B4SC is unlikely, we believe that a greater effort is required to reach the most vulnerable families to ensure that more children who would benefit from the B4SC will get access to the interventions that arise from it. This will require greater outreach and public awareness, but also examining whether access and cultural relevance of the B4SC could be improved. Interventions such as phone, letter or text message reminders have been shown to increase the uptake of health checks and are one option that could be explored to increase B4SC uptake. ${ }^{50} 51$

An area where there has been some success in getting increased services to hard-to-reach populations has been through mobile programmes and services. ${ }^{52} 53$ For example, in America, community health vans have shown success in reaching underserved populations such a low-income minority groups and immigrants for a range of health needs including earlier access to prenatal care and disease prevention screening. ${ }^{54-56}$ The Family Van run by Harvard Medical School offers a diverse range of health services and has saved an estimated $\$ 2.8$ million in avoided emergency room visits over the last 5 years with an estimated $\$ 23$ saving per $\$ 1$ spent. ${ }^{57}$ In addition, direct contact with those not participating should be considered with a greater push to ensure that those with characteristics of vulnerability are encouraged to attend. Further research is necessary on barriers to attendance identified and remedial action taken.

We have not followed children to determine whether missing a B4SC does in fact have an impact on later life outcomes, and this clearly needs to be assessed. We plan to address this question in future work, although the limited time series for the B4SC means that we will only be able to examine outcomes up to age 12 years.

\section{CONCLUSION}

Using a rich and diverse range of measures, we find that children with indicators of socioeconomic deprivation or poor health are less likely to participate in the B4SC and as such they may miss referrals for programmes and interventions that may increase their readiness to enter school. We believe the patterns we observe in B4SC participation suggest a potential reinforcing of existing inequalities and require increased effort to ensure that all children are tested and screened and that those with the greatest need get access to health services, programmes and interventions.

Contributors RA, BM, BJT and SG conceived the study. SG extracted data and did the main data analysis. NS provided statistical advice. All authors wrote and reviewed the manuscript, gave critical feedback and approved the final version for publication.

Funding This study was funded by A Better Start - National Science Challenge, New Zealand Ministry for Business, Innovation and Employment.

Disclaimer Access to the data used in this study was provided by Statistics New Zealand under conditions designed to give effect to the security and confidentiality provisions of the Statistics Act 1975. The results presented in this study are the work of the authors, not Statistics NZ.

Competing interests None declared.

Patient consent for publication Not required.

Provenance and peer review Not commissioned; externally peer reviewed.

Data sharing statement Due to privacy regulations around the Integrated Data Infrastructure, data from this study are not available for sharing.

Open access This is an open access article distributed in accordance with the Creative Commons Attribution Non Commercial (CC BY-NC 4.0) license, which permits others to distribute, remix, adapt, build upon this work non-commercially, and license their derivative works on different terms, provided the original work is properly cited, appropriate credit is given, any changes made indicated, and the use is non-commercial. See: http://creativecommons.org/licenses/by-nc/4.0/.

\section{REFERENCES}

1. Wilson $\mathrm{P}$, Wood R, Lykke $\mathrm{K}$, et al. International variation in programmes for assessment of children's neurodevelopment in the community: Understanding disparate approaches to evaluation of motor, social, emotional, behavioural and cognitive function. Scand J Public Health 2018;46:805-16.

2. Welch NM, Saulsbury FT, Kesler RW. The value of the preschool examination in screening for health problems. J Pediatr 1982;100:232-4.

3. Hall DM, Stewart-Brown S. Screening in child health. Br Med Bull 1998;54:929-43.

4. Ministry of Health. Well Child / Tamariki Ora Programme Practitioner Handbook: Supporting families and whānau to promote their child's health and development - Revised 2014. Wellington: Ministry of Health, 2013.

5. Ministry of Health. About primary health organisations. 2018 https:// www.health.govt.nz/our-work/primary-health-care/about-primaryhealth-organisations. 
6. Ministry of Health. B4 School Check information for the health sector. 2016 http://www.health.govt.nz/our-work/life-stages/child-health/b4school-check/b4-school-check-information-health-sector

7. Ministry of Health. Access to primary care as at October 2015: New Zealand Government. 2017 https://www.health.govt.nz/our-work/ primary-health-care/about-primary-health-organisations/enrolmentprimary-health-organisation

8. Søgaard AJ, Selmer R, Bjertness E, et al. The Oslo Health Study: The impact of self-selection in a large, population-based survey. Int $J$ Equity Health 2004;3:3.

9. Holland C, Cooper Y, Shaw R, et al. Effectiveness and uptake of screening programmes for coronary heart disease and diabetes: a realist review of design components used in interventions. BMJ Open 2013;3:e003428.

10. Harte E, MacLure C, Martin A, et al. Reasons why people do not attend NHS Health Checks: a systematic review and qualitative synthesis. Br J Gen Pract 2018;68:e28-e35.

11. Hoebel J, Starker A, Jordan S, et al. Determinants of health check attendance in adults: findings from the cross-sectional German Health Update (GEDA) study. BMC Public Health 2014;14:913.

12. Dryden R, Williams $B$, McCowan $C$, et al. What do we know about who does and does not attend general health checks? Findings from a narrative scoping review. BMC Public Health 2012;12:723.

13. Waller D, Agass M, Mant D, et al. Health checks in general practice: another example of inverse care? BMJ 1990;300:1115-8.

14. Freed GL, Clark SJ, Pathman DE, et al. Influences on the receipt of well-child visits in the first two years of life. Pediatrics 1999;103(4 Pt 2):864-9.

15. Wood R, Stirling A, Nolan C, et al. Trends in the coverage of 'universal' child health reviews: observational study using routinely available data. BMJ Open 2012;2:e000759.

16. Søndergaard G, Biering-Sørensen S, Michelsen SI, et al. Nonparticipation in preventive child health examinations at the general practitioner in Denmark: a register-based study. Scand J Prim Health Care 2008;26:5-11.

17. Tudor Hart J. The inverse care law. The Lancet 1971;297:405-12.

18. National Research Council. Early childhood assessment: why, what, and how. In: Snow CE, Van Hemel SB, eds. Washington, DC: The National Academies Press, 2008:500.

19. Alexander KE, Mazza D. The Healthy Kids Check - is it evidencebased? Med J Aust 2010;192:207.

20. Guevara JP, Gerdes M, Localio R, et al. Effectiveness of developmental screening in an urban setting. Pediatrics 2013;131:30-7.

21. US Preventive Services Task Force. Screening and interventions for overweight in children and adolescents: recommendation statement. Pediatrics 2005;116:205-9.

22. Statistics New Zealand. Integrated data infrastructure. https://www. stats.govt.nz/integrated-data/integrated-data-infrastructure/.

23. Ministry of Health. The B4 school check: a handbook for practitioners. Wellington: Ministry of Health, 2008.

24. Ministry of Health. B4 School Check information for early learning services. 2015 https://www.health.govt.nz/our-work/life-stages/childhealth/b4-school-check/b4-school-check-information-early-learningservices.

25. Ministry of Education. Indicator Report: Prior Participation in ECE. Wellington: Ministry of Education, 2017

26. Ministry of Health. District Health Boards. https://www.health.govt. nz/new-zealand-health-system/key-health-sector-organisations-andpeople/district-health-boards.

27. Ministry of Health. Personal communication: B4 School completion rates by ethnicity 2017.

28. Zhao J, Gibb S, Jackson R, et al. Constructing whole of population cohorts for health and social research using the New Zealand Integrated Data Infrastructure. Aust N Z J Public Health 2018;42:382-8.

29. Gibb S, Bycroft C, Matheson-Dunning N. Identifying the New Zealand resident population in the Integrated Data Infrastructure (IDI. Wellington: Statistics New Zealand, 2016.

30. Black A. The IDI prototype spine's creation and coverage. Wellington, New Zealand: Statistics New Zealand, 2016

31. Reid G, Bycroft C, Gleisner F. Comparison of ethnicity information in administrative data and the census. Wellington, New Zealand: Statistics New Zealand, 2016.

32. Fahy KM, Lee A, Milne BJ. New Zealand socio-economic index 2013, 2017.
33. Atkinson J, Salmond C, Crampton P. NZDep2013 index of deprivation. Wellington: Ministry of Health, 2014.

34. Statistics New Zealand. Statistical Standard for Meshblock. http:// archive.stats.govt.nz/methods/classifications-and-standards/ classification-related-stats-standards/meshblock.aspx.

35. Statistics New Zealand. Classifications and related statistical standards: Urban Area Statistics New Zealand. 2016 http://www. stats.govt.nz/methods/classifications-and-standards/classificationrelated-stats-standards/urban-area.aspx.

36. Ministry of Health. Annual Data Explorer 2016/17: New Zealand Health Survey. 2017 https://minhealthnz.shinyapps.io/nz-healthsurvey-2016-17-annual-update.

37. Morton S, Grant C, Berry SD, et al. Growing Up in New Zealand: A longitudinal study of New Zealand children and their families. Now We Are Four: Describing the preschool years. 2017.

38. Premium Research Limited. Before School Checks Consumer Research: Report commissioned by the Health Promotion Agency. Wellington: Health Promotion Agency, 2014.

39. Ministry of Health. Find a Well Child Tamariki Ora provider 2016 https://www.health.govt.nz/your-health/pregnancy-and-kids/ services-and-support-you-and-your-child/well-child-tamariki-oravisits/find-well-child-tamariki-ora-provider.

40. Sadler L, Priest P, Peters J, et al; Cervical cancer audit report, 2000.

41. Ministry of Health. Report on Maternity: Maternal and newborn information 2003. Wellington, New Zealand: Ministry of Health, 2006.

42. Davis P, Lay-Yee R, Dyall L, et al. Quality of hospital care for Māori patients in New Zealand: retrospective cross-sectional assessment. The Lancet 2006;367:1920-5.

43. Jeffreys M, Stevanovic V, Tobias M, et al. Ethnic inequalities in cancer survival in New Zealand: linkage study. Am J Public Health 2005:95:834-7.

44. Lee $\mathrm{CH}$, Duck IM, Sibley CG. Ethnic inequality in diagnosis with depression and anxiety disorders. N Z Med J 2017;130:10-20.

45. Pledger MJ, Cumming J, Burnette M, et al. Unmet need of GP services in Pacific people and other New Zealanders. N Z Med J 2011;124:35-45

46. Ministry of Social Development. The Social Report $2016-T e$ pūrongo oranga tangata. Wellington: Ministry of Social Development, 2016.

47. Simpson J, Duncanson M, Oben G, et al; The Health Status of Pacific Children and Young People in New Zealand 2015 (Pacific Child and Youth Health) New Zealand Child and Youth Epidemiology Service, 2017

48. Irwin LG, Siddiqi A, Hertzman G. Early child development: A powerfu equalizer: Human Early Learning Partnership (HELP. Vancouver, BC 2007

49. Spencer N; ESSOP. European Society for Social Pediatrics and Child Health (ESSOP)* Position Statement: Social inequalities in child health - towards equity and social justice in child health outcomes. Child Care Health Dev 2008;34:631-4.

50. Alpsten T. Saving lives through effective patient engagement around NHS health checks. Clinical Governance: An International Journal 2015;20:108-12

51. Gidlow CJ, Ellis NJ, Riley V, et al. Randomised controlled trial comparing uptake of NHS Health Check in response to standard letters, risk-personalised letters and telephone invitations. BMC Public Health 2019;19:224.

52. Yu SWY, Hill C, Ricks ML, et al. The scope and impact of mobile health clinics in the United States: a literature review. Int J Equity Health 2017;16:178.

53. Brown-Connolly NE, Concha JB, English J. Mobile health is worth it! Economic benefit and impact on health of a population-based mobile screening program in new Mexico. Telemed J E Health 2014;20:18-23.

54. Edgerley LP, El-Sayed YY, Druzin ML, et al. Use of a community mobile health van to increase early access to prenatal care. Matern Child Health J 2007;11:235-9.

55. O'Connell E, Zhang G, Leguen F, et al. Impact of a mobile van on prenatal care utilization and birth outcomes in Miami-Dade County. Matern Child Health J 2010;14:528-34

56. Hill C, Zurakowski D, Bennet J, et al. Knowledgeable Neighbors: a mobile clinic model for disease prevention and screening in underserved communities. Am J Public Health 2012;102:406-10.

57. The Family Van: Harvard Medical School. Our impact 2018 http:// www.familyvan.org/impact/. 